\title{
Eliminating Plasmodium falciparum in Hainan, China: a study on the use of behavioural change communication intervention to promote malaria prevention in mountain worker populations
}

\author{
Chang-hua He ${ }^{\dagger}$, Xi-min $\mathrm{Hu}^{\dagger}$, Guang-ze Wang ${ }^{\dagger}$, Wei Zhao, Ding-wei Sun, Yu-chun Li, Chun-xiang Chen,
} Jian-wei Du ${ }^{*+}$ and Shan-qing Wang ${ }^{*+}$

\begin{abstract}
Background: In the island of Hainan, the great majority of malaria cases occur in mountain worker populations. Using the behavioral change communication (BCC) strategy, an interventional study was conducted to promote mountain worker malaria prevention at a test site. This study found the methods and measures that are suitable for malaria prevention among mountain worker populations.

Methods: During the Plasmodium falciparum elimination stage in Hainan, a representative sampling method was used to establish testing and control sites in areas of Hainan that were both affected by malaria and had a relatively high density of mountain workers. Two different methods were used: a BCC strategy and a conventional strategy as a control. Before and after the intervention, house visits, core group discussions, and structural surveys were utilized to collect qualitative and quantitative data regarding mountain worker populations (including knowledge, attitudes, and practices [KAPs]; infection status; and serological data), and these data from the testing and control areas were compared to evaluate the effectiveness of BCC strategies in the prevention of malaria.

Results: In the BCC malaria prevention strategy testing areas, the accuracy rates of malaria-related KAP were significantly improved among mountain worker populations. The accuracy rates in the 3 aspects of malaria-related KAP increased from $37.73 \%, 37.00 \%$, and $43.04 \%$ to $89.01 \%, 91.53 \%$, and $92.25 \%$, respectively. The changes in all 3 aspects of KAP were statistically significant $(p<0.01)$. In the control sites, the changes in the indices were not as marked as in the testing areas, and the change was not statistically significant $(p>0.05)$. Furthermore, in the testing areas, both the percentage testing positive in the serum malaria indirect fluorescent antibody test (IFAT) and the number of people inflicted decreased more significantly than in the control sites $(p<0.01)$.

Conclusion: The use of the BCC strategy significantly improved the ability of mountain workers in Hainan to avoid malarial infection. Educational and promotional materials and measures were developed and selected in the process, and hands-on experience was gained that will help achieve the goal of total malaria elimination in Hainan.
\end{abstract}

\footnotetext{
*Correspondence: djwei22@sohu.com; wangsqkevin@163.com

${ }^{\dagger}$ Equal contributors

Hainan Provincial Center for Disease Control and Prevention, No.44, Haifu Road, 570203 Haikou, Hainan province, China
} 


\section{Background}

The island of Hainan is the southernmost island and province in China. It is situated between latitudes $18^{\circ} 10^{\prime}$ $\mathrm{N}$ and $20^{\circ} 10^{\prime} \mathrm{N}$ and longitudes $108^{\circ} 37^{\prime} \mathrm{E}$ and $111^{\circ} 03^{\prime} \mathrm{E}$. Hainan Island is a tropical area with a climate and environment ideally suited for the breeding of the mosquito varieties Anopheles minimus and Anopheles dirus, both vectors of which are malaria transmission. Malaria is actively transmitted throughout the year in Hainan, and historical data show that the island was once the site of the most devastating malaria epidemics in China, especially of the P. falciparum strain. The Anopheles minimus distribution covers almost the entire island; in 1955, the percentage of residents in the south-central mountain region carrying the parasite was over $50 \%$, and the disease rate was as high as 1,036.6/10,000 [1-3].

Based on estimates by the WHO, the global rate of malaria deaths decreased by $26 \%$ between the years 2000 and 2010. However, in 2010, there were still 219 million people infected, resulting in 660,000 deaths that year [4]. In China, due to the unwavering efforts of the government and all levels of malaria prevention personnel, malaria epidemics throughout China have also declined substantially in the past 50 years [5]. Although China and Hainan Island have made good progress in the fight against malaria, in the previous malaria-control strategies, there was a lack of recognition, understanding, and application of BCC strategies [6-8]. Hainan Island has 50 years of malaria control records without any systematic research regarding $\mathrm{BCC}$ strategies, and there is a similar absence of literature regarding this strategy in other parts of China $[3,9,10]$. In contrast, in an earlier malaria control stage, researchers conducted an intervention study in parts of Hainan Island and obtained good results in the research stage; however, these intervention measures encountered a lack of persistence or long-term acceptance rates. Therefore, these intervention measures have not been widely implemented, especially given the overall decline of malaria cases in Hainan [10-14].

According to WHO recommendations, when the malaria incidence rates in a country or region decrease to a very low level, it is necessary to conduct official efforts to eradicate malaria [15]. Considering this guideline, in May 2010, 13 Chinese government departments jointly developed and released a plan to eliminate malaria in most of the country by 2015 and to achieve the goal of national malaria elimination by 2020 [16]. Hainan has effectively reduced the incidence and mortality of malaria, and malaria-endemic areas continue to shrink [17-19]. In recent years, especially since 2003, malaria control in Hainan has received strong support from the Chinese government and the first and fifth rounds of the Global Fund Malaria Project [20], greatly enhancing the ability to control the spread of malaria in Hainan Island and reducing local malaria epidemic levels to their lowest point in history. Hainan has two kinds of malaria (Plasmodium falciparum and Plasmodium vivax) and, according to 2012 Chinese reports on infectious diseases, Hainan Island has gone through three consecutive years without any reports of local $P$. falciparum malaria cases. By the standards of the World Health Organization, Hainan Province has achieved the elimination of $P$. falciparum malaria [5,21].

In the mountain areas of Hainan, most residents make a living by farming, and historical data show that most cases of malaria infection in Hainan have their source in populations that live or work is at high risk for malaria infection in the mountains [22-24]. The vast majority of these people are planters of betel nuts and rubber, and in the process of agricultural development, they inevitably must stay overnight in the mountains. They mostly live in temporary dormitories close to Anopheles breeding sites. These living conditions are poor, and the workers are scattered; consequently, measures to control mosquitoes and to diagnose and treat malaria in a timely manner are difficult to implement, which is a major problem confronting anti-malaria interventions. Ensuring that malaria prevention is effectively conducted among mountain worker populations will play a decisive role in achieving the future elimination of $P$. falciparum and Plasmodium vivax malaria in Hainan Island.

To eliminate malaria, residents in the target area must have a high level of knowledge regarding the transmission and prevention of malaria and must maintain a high level of participation [16,25-29]. Behavioural change communication (BCC) is a behaviour-shaping or -changing measure that mainly aims to use information education communication (IEC) to improve the knowledge level of the population, create a supportive social environment that is conducive to forming target behaviours, and provide material and moral support to help overcome factors that would affect target behaviours [25,30]. Using BCC strategies to promote healthy behaviours against malaria is based on verified malaria control theories and behaviour change models and examples. Through the development of appropriate actions and information that are acceptable to the community - taking advantage of exchanges within the community to spread related information and behaviour - and the honest exchange of dialogue, the attitude and participation of residents in malaria prevention and treatment can be improved; the end goal is to promote positive behaviour, build community participation, and create a strong prevention system [31,32].

Between March 2009 and December 2012, the researchers selected six towns (farms) with concentrated mountain worker populations in the south-central mountain areas of Hainan to conduct research trials on using $\mathrm{BCC}$ intervention strategies for the promotion of 
malaria prevention. By analysing malaria-related KAPs and changes in serum markers before and after the intervention, the authors explored and accumulated methods to promote malaria prevention in mountain worker populations using the BCC strategy and thereby how to accelerate the progress of malaria elimination in Hainan.

\section{Methods}

\section{Sampling of mountain worker populations}

Among the towns and cities in Hainan that were malaria-endemic and had higher concentrations of mountain workers, representative sampling methods were used to arrange the cities, towns, and farms based on their malaria incidence rates in 2007-2008. One farm and one town with high rates of malaria and large numbers of mountain workers were chosen to be surveyed. Wanning (Nanlin farm and Nanqiao town) and Ledong (Lezhong farm and Baoguo farm) were chosen as testing areas, while the Dongfang region (Donghe town and Jiangbian town) was chosen as a control site (Figure 1). The areas were all greater than $100 \mathrm{~km}$ apart, and the residents of each area were largely isolated from those of other areas. Surveys included all mountain workers within the towns or farms that were at least 15 years of age and had lived in the area for at least three years. At the time of the final survey, 100 mountain workers were randomly selected from the testing areas to survey their feedback on BCC intervention material.

\section{Malaria serum samples and control (positive and negative) grouping}

The inclusion criteria were as follows: (1) individuals who had lived in the selected mountain areas for $\geq$ three years or who had worked in the mountains for $\geq$ three years, including local and migrant workers; and (2) individuals with titers $\geq 1: 20$ in number when tested with IFAT based on malaria serological survey methods [33]. Workers who had entered the mountains recently or occasionally, who did not reside continuously in the selected regions, or who were under 15 years of age were excluded.

\section{Development of the BCC intervention material}

After a needs evaluation for malaria-related IEC and BCC in Hainan's mountain worker populations [25], and after referencing domestic and foreign educational materials and methods (especially those of Hainan), the interventional methods and educational materials were designed for this study, using the following steps (Figure 2).

Techniques for disseminating the interventional information Based on the needs evaluation, communication materials were chosen that were practical and would likely be favored by mountain workers (such as straw hats, slogan, towels, fans, calendars, medicine bags, folding leaflets, signs, public network, posters, and T-shirts), with more than 10 forms of media overall. A public health website and video compact disc (VCD) materials were created

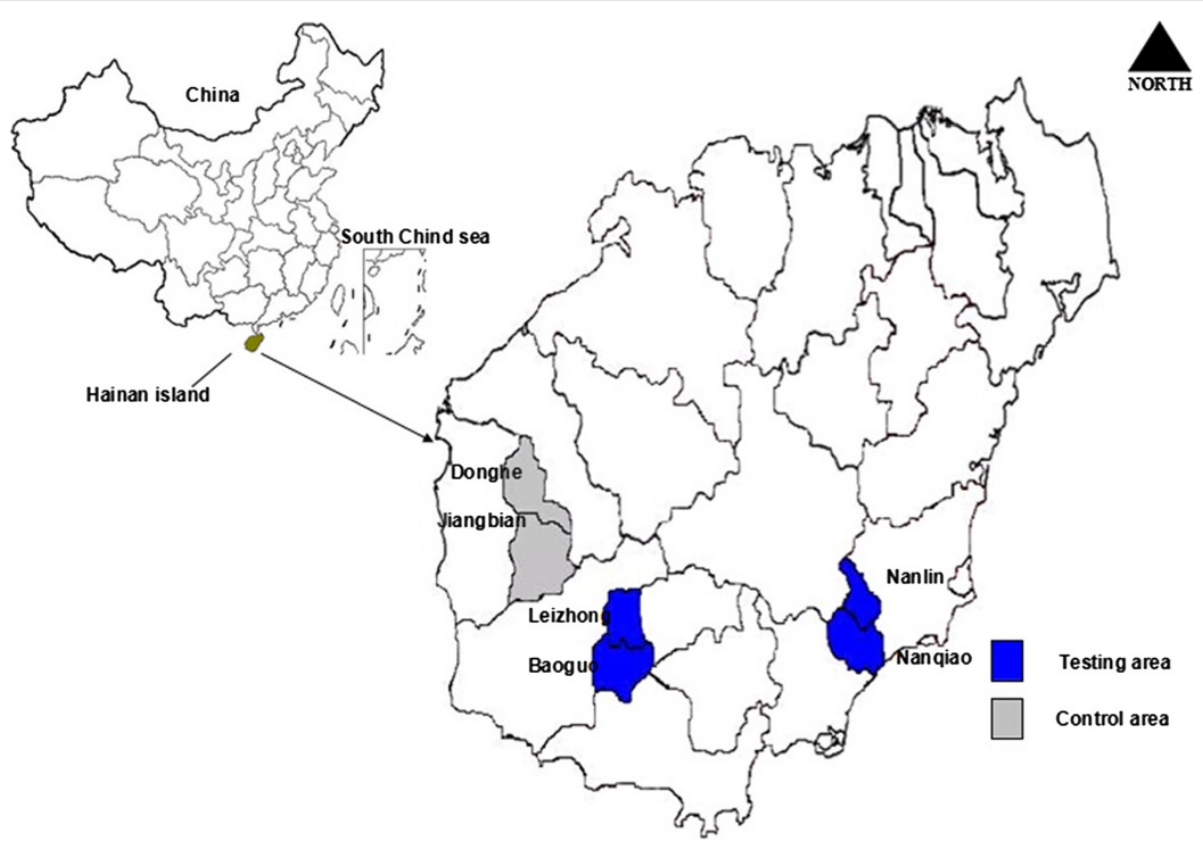

Figure 1 Map of China and Hainan island and intervention classification area. 


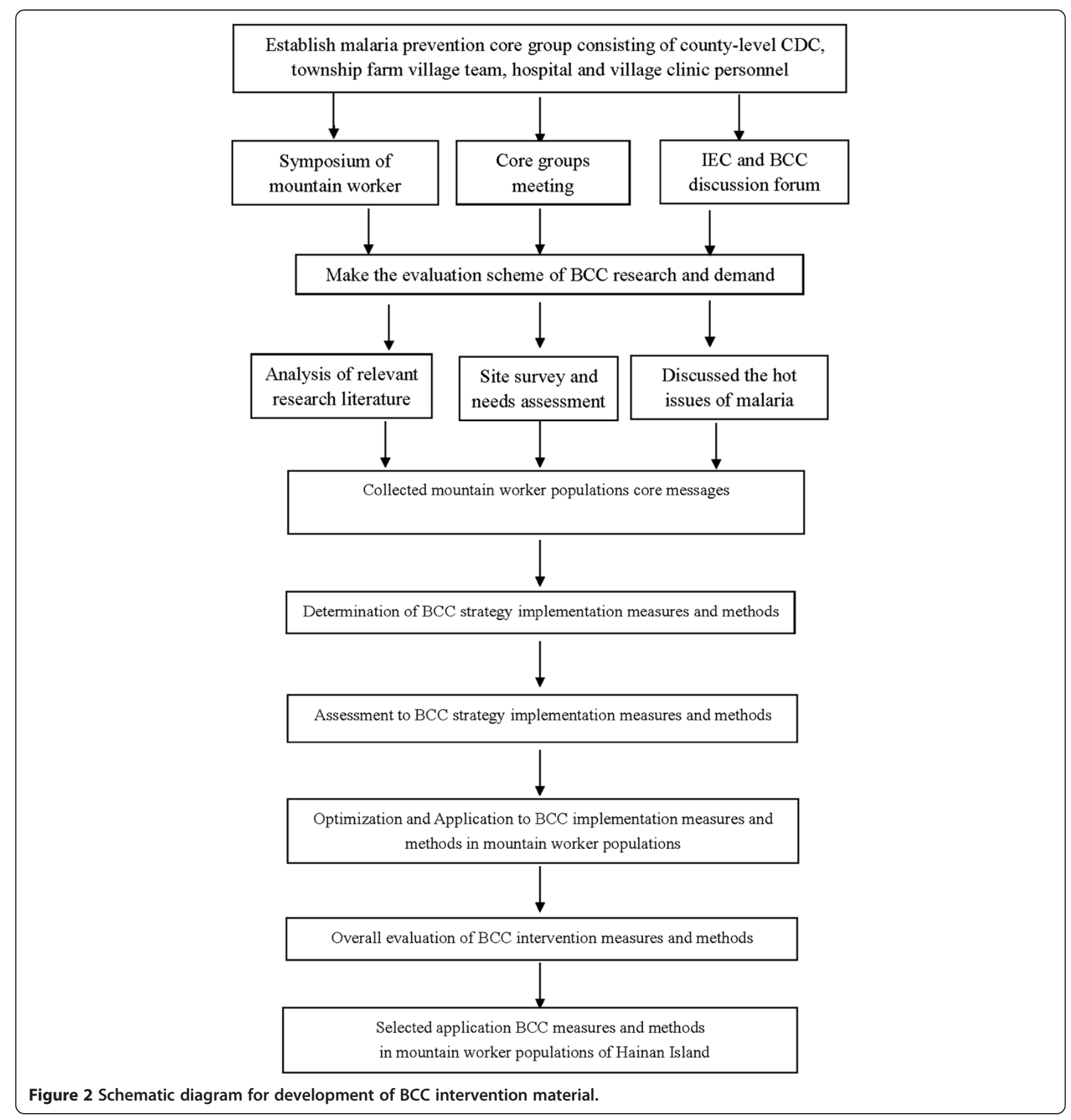

taking into account local customs and ethnic and linguistic characteristics.

\section{Intervention methods}

During the period between October 2009 and October 2012, only passive anti-malarial measures such as free diagnosis and treatment, early treatment, and indoor residual spraying were performed in the control areas. In the testing areas, besides the routine measures, the following measures were conducted: (i) the establishment of malaria prevention core groups consisting mainly of town farm teams, health institutions, town health and village clinic personnel, and strengthening of community promotion and participation, with a system of incentives for discovering malaria on a regular basis; (ii) the distribution of long-lasting insecticide-treated nets (LLINs) and insecticide-treated nets (ITNs), which were treated twice a year in the spring and fall, to the residents, and the provision of indoor residual spraying services; (iii) needs assessments for KAP baseline indicators and the 
consequent development of a comprehensive model of malaria-related BCC policy interventions (seminars, lectures, leaflets, posters, audio-visual medias, etc.) for educational and promotional purposes, with a frequency of 2-3 times/year; (iv) using the public health network Liquid Crystal Display (LCD) digital media platforms built by the Hainan government in health provider sites, community health service stations, urban and rural hospitals, pharmacies and other public places, malaria-related health information based primarily on the needs of the mountain worker populations was put on rolling display every day, in both the Hainan dialect and Mandarin.

The core messages in the interventional media and promotional materials were the following: (1) mosquitoes bite people and spread malaria; (2) if you experience chills and fever, get urgent medical attention; (3) antimalarial medication is free, and the therapy must be thorough; (4) malaria is a preventable and treatable parasitic disease; (5) eliminating the hazards of malaria is the honor of this generation and will benefit future generations; (6) early diagnosis and treatment of malaria is essential; (7) for the ecological management of mosquito breeding sites in residential areas, employ reasonable indoor residual spraying, ITNs, and LLINs. The media messages included voices both in Mandarin and in the Hainan dialect.

\section{Survey information collection}

After reviewing the historical data, qualitative and quantitative surveys were designed, which were subjected to reviews by specialists, pre-investigated, and then modified. The malaria-related KAP questionnaire concerned the following: (1) general demographic characteristics: gender, age, ethnicity, commonly used language, education level and other demographic characteristics; (2) mosquito control- and prevention-related basic knowledge; (3) malaria control- and prevention-related basic knowledge; (4) malaria control- and prevention-related basic attitudes; (5) malaria prevention- and treatmentrelated practices and behaviours, including the type of work in the mountains; living conditions and use of bed nets in the mountains; frequency of overnight stays in the mountains; use of preventative medication before overnight stays in the mountains; whether the subject received malaria-prevention education, used a bed net at home, accepted ITNs, or actively used bed nets in the mountains; whether the subject was taking preventive measures during overnight stays in the mountains (such as bed nets, insect repellents, making a fire or spraying insecticide around the temporary dormitories); whether the subject habitually slept outdoors; whether the subject was aware of the symptoms of malaria; and so on. There were five aspects and 40 problems for the malaria control and prevention-related KAPs. After the intervention,
100 randomly selected mountain workers from the testing areas were asked whether they could recall the various promotional materials and their core messages, as well as the degree to which they liked these materials, to survey their feedback regarding the BCC intervention material. The investigators were mainly public health physicians from county-level CDC and local hospitals in the testing regions, with a total number of 18 , and they were all trained together by 4 specialists from the Hainan Provincial CDC. The interviews took the form of in-home, one-on-one, face-to-face visits; upon completion of the questionnaire, blood was collected from the finger or earlobe, placed on filter paper, and coated on a microscopic slide. During March-April 2009 and NovemberDecember 2012, mountain workers in the test area and control area were tested for malaria-related KAP, infection, serum markers, and blood parasite rate, and these data were used as the baseline and endpoint of the investigation.

\section{Malaria infection data and blood tests}

The Chinese Infectious Disease Network reporting system was used to track the number of people infected with malaria in the testing and control sites. Two local qualified professionals performed the microscopic examinations for each area.

\section{Malaria serum antibody tests}

The subjects' earlobe or fingertip blood was collected and dripped into a circle on filter paper $(20 \mu \mathrm{L}$ of blood fills the circle), with 1 round drop of blood per filter paper. The blood samples were allowed to dry naturally and were then stored in a plastic bag with a drying agent at $-20^{\circ} \mathrm{C}$. Blood samples were sent to the Hainan Province Center for Disease Control and Prevention's National Malaria Laboratory, where they were subjected to a serum Indirect Fluorescent Antibody Test (IFAT) in accordance with the "Manual of Malaria Control" [33]. Antibody titers $\geq 1: 20$ were regarded as positive for malaria antibodies. Plasmodium cynomolgi antigen from cynomolgus macaques was used for detection [34], provided by the Chinese Center for Disease Control and Prevention's Institute of Parasitic Diseases.

\section{Malaria prevention knowledge and attitudes survey}

Answering at least six questions correctly was considered passing. The scoring criteria were as follows: (1) answer deemed correct, 4 points; (2) answer deemed basically correct, 2 points; (3) answers that did not meet the standards or were lacking were deemed incorrect, 0 points. Scores $\geq 24$ points were considered passing grades, while those $<24$ were considered failing grades. 


\section{Malaria prevention practices survey}

The survey included questions such as whether the subject had the habit of sleeping outdoors, whether mosquito prevention measures were taken (bed nets, mosquito incense, or mosquito repellant), willingness to take a blood test upon getting a fever, and whether insecticide-treated bed nets were used, etc., with 10 questions in total. Eight good behaviours constituted a passing grade. The scoring criteria were: (1) answer deemed correct, 4 points; (2) answer deemed basically correct, 2 points; (3) answers that did not meet the standards or were lacking were deemed incorrect, 0 points. Scores $\geq 32$ points were considered passing grades, while those $<32$ were considered failing grades.

After the surveys were collected and organized, two people independently entered the data using EpiData 3.1 software, and they were compared to ensure they were identical and logically consistent. The data were then imported into SPSS 17.0 for statistical analysis, with a statistical significance level of $\alpha=0.05$.

\section{Results}

\section{General information}

Before the BCC intervention strategy, there were 40,746 people in the testing area and 22,875 people in the control area in 2009, and the surveyed mountain worker population totaled 925 people; this number included 546 people in the testing area and 379 in the control area, with mean ages of $(41.40 \pm 9.82)$ years and $(39.84 \pm$ $10.30)$ years, respectively. There were 495 people of the Li ethnicity in the testing area, and 379 people in the control area usually communicated in the Hainan dialect. After the intervention, there were 41,244 people in the testing area and 23,741 people in the control area; in 2012, the surveyed population totaled 948 people, with 555 in the testing area and 393 in the control area, and the mean ages were $(45.41 \pm 10.40)$ years and $(47.08 \pm$
11.33) years, respectively. There were 523 people of the Li ethnicity in the testing area, and 388 people in the control area usually communicated in the Hainan dialect. There were no statistically significant differences between the mountain worker populations of the testing and control areas in terms of gender, mean age, or educational level, both before and after the BCC strategy intervention; thus, the 2 populations were comparable.

\section{Malaria-related KAP survey}

The results show that before the $\mathrm{BCC}$ intervention strategies, the accuracy rates of malaria-related KAP knowledge and proper behaviour were low in the mountain worker populations of both the testing and control areas. In all three aspects, regardless of gender, age group, or education level, no group exceeded $50 \%$ in terms of knowledge or correct behaviour (Table 1). Table 2 compares the results of the test area and the control area before intervention.

\section{Serum malaria IFAT and baseline parasite-infection rate} Malaria serology results from the testing and control areas are shown in Table 3. Aside from the data shown, in 2008, there were 10 cases of malaria infection reported in the area, including seven in the testing area and three in the control area.

\section{Effectiveness of the BCC intervention strategy}

Based on changes in the malaria-related KAP in mountain workers in the test and control areas after BCC intervention (Table 4), there was a greater change in knowledge, attitudes and practices in the test area compared with the control area, and this difference is statistically significant $(p<0.01)$. Figure 3 shows a comparison of changes in the malaria-related KAP scores' accuracy rate between the test area and the control area.

Table 1 Baseline of accuracy rate of malaria related KAP among mountain worker populations

\begin{tabular}{|c|c|c|c|c|c|c|c|c|c|}
\hline \multirow[t]{2}{*}{ Content } & \multirow[t]{2}{*}{ Group } & \multicolumn{4}{|c|}{ Testing area } & \multicolumn{4}{|c|}{ Control area } \\
\hline & & Population & $\mathrm{K}(\%)$ & $A(\%)$ & $\mathrm{P}(\%)$ & Population & K (\%) & $A(\%)$ & $\mathrm{P}(\%)$ \\
\hline \multirow[t]{2}{*}{ Gender } & Male & 316 & $121(38.29)$ & $112(35.44)$ & $140(44.3)$ & 181 & $84(46.41)$ & $75(41.44)$ & $81(44.75)$ \\
\hline & Female & 230 & $85(36.96)$ & $90(39.13)$ & $95(41.30)$ & 198 & $69(34.85)$ & $74(37.37)$ & $87(43.94)$ \\
\hline \multirow[t]{2}{*}{ Age group (years) } & $<20$ & 47 & $20(42.55)$ & $22(46.81)$ & $19(40.43)$ & 38 & $18(47.37)$ & $18(47.37)$ & $15(39.47)$ \\
\hline & $20-40$ & 325 & $103(31.69)$ & $115(35.38)$ & $132(40.62)$ & 264 & 99 (37.50) & $101(38.26)$ & $113(42.80)$ \\
\hline \multirow[t]{5}{*}{ Educational status } & $>40$ & 174 & $83(47.70)$ & $65(37.36)$ & $84(48.28)$ & 77 & $36(46.75)$ & $30(38.96)$ & $40(51.95)$ \\
\hline & Illiteracy/Semiliterate & 38 & $10(26.32)$ & 9 (23.68) & $17(44.74)$ & 121 & $39(32.23)$ & $4234.71)$ & $48(39.67)$ \\
\hline & Primary education & 105 & $33(31.43)$ & 35 (33.33) & $47(44.76)$ & 225 & $101(44.89)$ & $90(40.00)$ & $100(44.44)$ \\
\hline & $\begin{array}{c}\text { Junior high school } \\
\text { and above }\end{array}$ & 403 & $163(40.45)$ & $158(39.21)$ & $171(42.43)$ & 33 & $13(39.39)$ & $17(51.52)$ & $20(60.61)$ \\
\hline & Sum & 546 & $206(37.73)$ & $202(37.00)$ & $235(43.04)$ & 379 & $153(40.37)$ & $149(39.31)$ & $168(44.33)$ \\
\hline
\end{tabular}


Table 2 The proper rate of the major indexes of malaria-related KAPs among mountain worker populations before intervention

\begin{tabular}{|c|c|c|c|c|c|c|}
\hline \multirow[t]{2}{*}{ Index } & \multicolumn{2}{|c|}{ Testing area } & \multicolumn{2}{|c|}{ Control area } & \multirow[t]{2}{*}{$x^{2}$} & \multirow[t]{2}{*}{$p$} \\
\hline & $\mathrm{n}$ & $\%$ & $\mathrm{n}$ & $\%$ & & \\
\hline How malaria is spread & 205 & 37.60 & 167 & 44.10 & 3.95 & $0.05^{*}$ \\
\hline Onset symptoms of malaria & 314 & 57.60 & 199 & 52.50 & 2.27 & 0.13 \\
\hline Types of malaria & 88 & 16.10 & 74 & 19.50 & 1.80 & 0.18 \\
\hline Malaria prevention methods & 190 & 34.80 & 112 & 29.60 & 2.80 & 0.09 \\
\hline Mosquito breeding grounds & 236 & 43.20 & 150 & 39.50 & 1.22 & 0.27 \\
\hline Anti-mosquito effect of insecticide treated bed nets & 210 & 38.50 & 164 & 43.20 & 2.15 & 0.14 \\
\hline Whether avoiding mosquito can prevent malaria & 264 & 48.30 & 209 & 55.10 & 4.13 & $0.04^{*}$ \\
\hline Using bed nets actively in the mountains & 68 & 12.50 & 53 & 14.00 & 0.46 & 0.50 \\
\hline Acceptance of information about malaria & 346 & 63.30 & 225 & 59.40 & 1.52 & 0.22 \\
\hline Preventive drugs for malaria & 106 & 19.50 & 78 & 20.70 & 0.19 & 0.66 \\
\hline Treatment drugs for malaria & 216 & 39.50 & 141 & 37.10 & 0.53 & 0.47 \\
\hline Method of preventive drugs & 53 & 9.70 & 41 & 10.90 & 0.30 & 0.58 \\
\hline Having a plan to prevent mosquitoes & 225 & 41.30 & 165 & 43.50 & 0.50 & 0.48 \\
\hline Having a plan to not sleep outdoors in the mountains & 239 & 43.70 & 143 & 37.60 & 3.37 & 0.07 \\
\hline Taking preventive measures while working in the mountains & 209 & 38.20 & 165 & 43.60 & 2.57 & 0.11 \\
\hline Percentage sleeping outdoors in the mountains & 179 & 32.78 & 136 & 35.90 & 0.96 & 0.33 \\
\hline Actual use of a bed net at home & 128 & 23.44 & 104 & 27.50 & 1.90 & 0.17 \\
\hline Accepting a blood test when having a fever & 238 & 43.59 & 206 & 54.30 & 10.38 & $0.00^{*}$ \\
\hline Accepting ITNs at home & 187 & 34.25 & 144 & 37.90 & 1.37 & 0.24 \\
\hline What to do when suffering from malaria & 327 & 59.80 & 233 & 61.40 & 0.24 & 0.63 \\
\hline
\end{tabular}

\section{* $p<0.05$.}

Nine hundred twenty-five persons (testing area, 546; control area, 379) participated in the survey before undergoing the BBC-strategy-intervention.

Comparison of knowledge, attitudes and practices (KAPs) after intervention

A comparison of the 20 major malaria-related KAP items in the test and control areas before and after the intervention yielded 14 items in which the percentage of correct or appropriate responses showed a statistically significant increase $(p<0.05)$. The general level of knowledge was higher in the test areas than in the control areas. In terms of attitudes and practices in the test areas, there was a marked increase in the avoidance of outdoor sleeping and in the conscious utilization of mosquito-protection measures $(p<0.05)$, but there were also decreases in a few items. In the indexes of the actual use of bed nets at home, accepting a blood test when having fever, and accepting ITNs at home, the percentages rose from $23.44 \%, 43.59 \%$, and $34.25 \%$ to $81.08 \%$,
85.23\%, and $92.61 \%$ after the intervention, respectively, and the percentage of sleeping outdoors in the mountains decreased from $32.78 \%$ to $5.05 \%$. These differences were statistically significant $(p<0.01)$. In the control areas, there were also increases in many indexes, but these were not significant compared with the testing area (Table 5).

\section{KAP summary before and after intervention}

The percentages of mountain workers in the test area who passed the knowledge $(\mathrm{K})$, attitudes $(\mathrm{A})$, and practices (P) sections of the questionnaire increased from $37.73 \%, 37.00 \%$, and $43.04 \%$ before the intervention to $89.01 \%, 91.53 \%$, and $92.25 \%$ after the intervention, respectively; all three differences were statistically significant $(p<0.01)$. With gender as a categorical variable,

Table 3 Results of the IFAT and blood smear test in the testing and control areas before intervention

\begin{tabular}{|c|c|c|c|c|c|c|}
\hline \multirow[t]{2}{*}{ Group } & \multirow[t]{2}{*}{ Population } & \multirow{2}{*}{$\begin{array}{c}\text { IFAT number } \\
\text { testing positive (\%) }\end{array}$} & \multicolumn{2}{|c|}{ GMRT } & \multicolumn{2}{|c|}{ Positive diagnosis with microscopic examination } \\
\hline & & & Positive & Total & Population & $\%$ \\
\hline Testing area & 546 & $22(4.03)$ & 27.41 & 10.42 & 1 & 0.18 \\
\hline Control area & 379 & $24(6.33)$ & 25.94 & 10.62 & 1 & 0.26 \\
\hline
\end{tabular}

IFAT = Indirect fluorescent antibody test. GMRT = Geometric mean reciprocal titer. IFAT Positive: $\geq 1: 20$. 
Table 4 Change in the accuracy rate of the malaria related KAP among mountain worker populations after intervention

\begin{tabular}{|c|c|c|c|c|c|c|c|c|c|}
\hline \multirow[t]{2}{*}{ Content } & \multirow[t]{2}{*}{ Group } & \multicolumn{4}{|c|}{ Testing area } & \multicolumn{4}{|c|}{ Control area } \\
\hline & & Population & $\mathrm{K}(\%)$ & A (\%) & $\mathrm{P}(\%)$ & Population & $\mathrm{K}(\%)$ & A (\%) & $\mathrm{P}(\%)$ \\
\hline \multirow[t]{2}{*}{ Gender } & Male & 295 & $249(84.41)$ & $257(87.12)$ & $263(89.15)$ & 201 & $91(45.27)$ & $93(46.27)$ & $84(41.79)$ \\
\hline & Female & 260 & $245(94.23)$ & $251(96.54)$ & $249(95.77)$ & 192 & $70(36.46)$ & $80(41.67)$ & $82(42.71)$ \\
\hline \multirow[t]{3}{*}{ Age group (years) } & $<20$ & 58 & $54(93.10)$ & $51(87.93)$ & $47(81.03)$ & 45 & $25(55.56)$ & $22(48.89)$ & 15 (33.33) \\
\hline & $20-40$ & 306 & $275(89.87)$ & $291(95.10)$ & $285(93.14)$ & 237 & $83(35.02)$ & $103(43.46)$ & $98(41.35)$ \\
\hline & $>40$ & 191 & 165 (86.39) & $166(86.91)$ & $180(94.24)$ & 111 & $53(47.75)$ & $48(43.24)$ & $53(47.75)$ \\
\hline \multirow[t]{4}{*}{ Educational status } & Illiterate/semiliterate & 47 & 43 (91.49) & $40(85.11)$ & $43(91.49)$ & 115 & $42(36.52)$ & $5(44.35)$ & $48(41.74)$ \\
\hline & Primary education & 121 & $107(88.43)$ & $104(85.95)$ & $111(91.74)$ & 231 & $102(44.16)$ & $99(42.86)$ & $93(40.26)$ \\
\hline & $\begin{array}{l}\text { Junior high school } \\
\text { and above }\end{array}$ & 387 & $344(88.89)$ & 364 (94.06) & $358(92.51)$ & 47 & $17(36.17)$ & $23(48.94)$ & 25 (53.19) \\
\hline & otal & 555 & 249 (89.01) & 508 (91.53) & $512(92.25)$ & 393 & 161 (40.97) & 173 (44.02) & $166(42.24)$ \\
\hline
\end{tabular}

$\mathrm{K}=$ Rate of malaria knowledge; $\mathrm{A}=$ Rate of correct attitude; $\mathrm{P}=$ Rate of good practice.

and comparing the malaria-related KAPs of mountain workers in the test area and control area against each other or against themselves with $\mathrm{X} 2$ tests, all comparisons showed statistically significant increases $(p<0.01$; Tables 6 and 7).

\section{Changes in malaria serology}

In the test area, the malaria IFAT positive rates fell from $4.03 \%$ before the intervention to $1.44 \%$ after the intervention; this difference was statistically significant $(\mathrm{p}<$ 0.01 ). The positive geometric mean reciprocal titer (GMRT) decreased from $27.41 \%$ to $21.81 \%$, and the overall geometric mean reciprocal titer (GMRT) decreased from $10.42 \%$ to $10.11 \%$. There was little change in each index in the control area, with no statistically significant differences $(p>0.05$; Table 8$)$.

\section{Changes in malaria infection rates}

The survey results showed that, in the testing area, the percentage of subjects with blood tests revealing a parasite infection decreased from $0.18 \%$ before the BCC intervention to 0 after the intervention, the malaria cases reported (including clinical diagnoses) decreased from seven to one, and the malaria incidence rate declined from 1.71 per $10,000(7 / 40,746)$ to 0.24 per 10,000 (1/ $41,244)$. In the control area, the blood test parasite infection rate was $0.26 \%$ before and $0.51 \%$ after the intervention; there were three malaria cases reported before and two malaria cases after the intervention. Moreover, the malaria incidence decreased from 1.31 per 10,000 (3/ $22,875)$ to 0.85 per $10,000(2 / 23,541)$.

\section{Overall evaluation of the BCC intervention content}

During the final survey, 100 mountain workers were randomly selected to provide feedback. They were asked whether they could recall the various promotional materials and their core messages and the degree to which they liked these materials. The results showed that over 90\% liked the materials (Figure 4).

\section{Discussion}

Through the literature and this survey, that the majority of mountain workers of the Li ethnicity usually communicate in the local Hainan dialect because they cannot

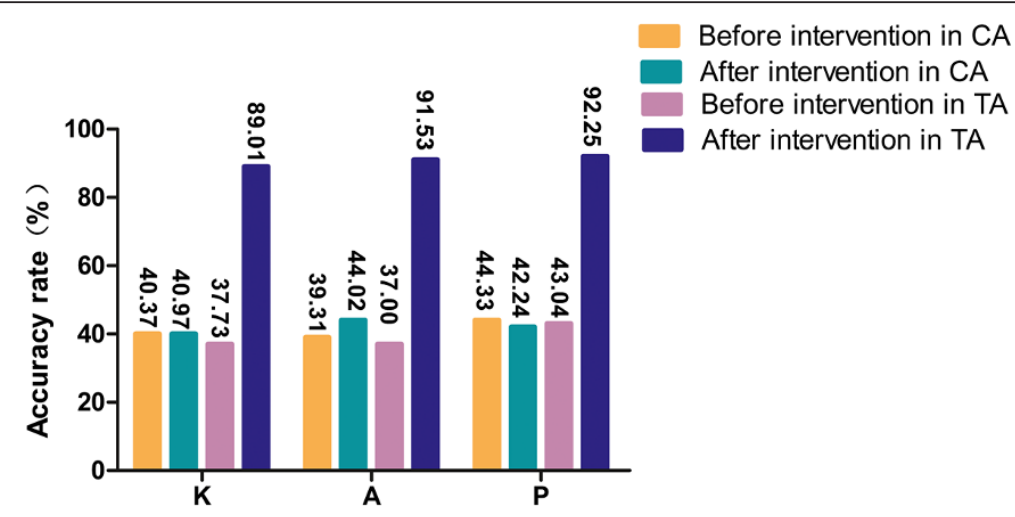

Figure 3 Comparison of changes in malaria-related KAP accuracy rate between testing and control area. ${ }^{*} \mathrm{CA}$ : control area; TA: testing area. 
Table $\mathbf{5}$ The proper rate of the major indexes of the malaria-related KAPs among mountain worker populations after intervention

\begin{tabular}{|c|c|c|c|c|c|c|}
\hline \multirow[t]{2}{*}{ Index } & \multicolumn{2}{|c|}{ Testing area } & \multicolumn{2}{|c|}{ Control area } & \multirow[t]{2}{*}{$x^{2}$} & \multirow[t]{2}{*}{$P$} \\
\hline & $\mathrm{n}$ & $\%$ & $\mathbf{n}$ & $\%$ & & \\
\hline How malaria is spread & 473 & 85.20 & 258 & 65.65 & 49.96 & $0.00^{*}$ \\
\hline Onset symptoms of malaria & 502 & 90.40 & 257 & 65.30 & 90.49 & $0.00^{*}$ \\
\hline Types of malaria & 114 & 20.60 & 8 & 22.50 & 0.47 & 0.49 \\
\hline Malaria prevention methods & 414 & 74.60 & 201 & 51.20 & 55.52 & $0.00^{*}$ \\
\hline Mosquito breeding grounds & 490 & 88.20 & 215 & 54.80 & 136.11 & $0.00^{*}$ \\
\hline Anti-mosquito effect of insecticide treated bed nets & 441 & 79.50 & 316 & 80.30 & 0.13 & 0.72 \\
\hline Whether avoiding mosquito can prevent malaria & 498 & 89.70 & 290 & 73.80 & 41.66 & $0.00^{*}$ \\
\hline Using bed nets actively in the mountains & 380 & 68.50 & 137 & 34.90 & 104.82 & $0.00^{*}$ \\
\hline Acceptance of information about malaria & 467 & 84.10 & 344 & 87.50 & 2.14 & 0.14 \\
\hline Preventive drugs for malaria & 228 & 41.10 & 155 & 39.50 & 0.26 & 0.61 \\
\hline Treatment drugs for malaria & 302 & 54.40 & 179 & 45.60 & 7.24 & $0.01^{*}$ \\
\hline Method of preventive drugs & 87 & 15.70 & 54 & 13.70 & 0.68 & 0.41 \\
\hline Having a plan to prevent mosquitoes & 513 & 92.50 & 217 & 55.30 & 179.96 & $0.00^{*}$ \\
\hline Having a plan to not sleep outdoors in the mountains & 485 & 87.40 & 264 & 67.20 & 56.67 & $0.00^{*}$ \\
\hline Taking preventive measures while working in the mountains & 459 & 82.70 & 241 & 61.30 & 54.44 & $0.00^{*}$ \\
\hline Percentage sleeping outdoors in the mountains & 28 & 5.05 & 105 & 26.70 & 89.60 & $0.01^{*}$ \\
\hline Actual use of a bed net at home & 450 & 81.08 & 191 & 48.60 & 110.85 & $0.00^{*}$ \\
\hline Accepting a blood test when having a fever & 473 & 85.23 & 274 & 69.60 & 33.11 & $0.00^{*}$ \\
\hline Accepting ITNs at home & 514 & 92.61 & 219 & 55.80 & 178.53 & $0.00^{*}$ \\
\hline What to do when suffering from malaria & 470 & 84.70 & 340 & 86.50 & 0.62 & 0.43 \\
\hline
\end{tabular}

\section{* $p<0.05$.}

Nine hundred forty-eight persons (testing area, 555; control area, 393) participated in the survey after undergoing the BBC-strategy-intervention.

understand or rarely use Mandarin in the test sites. Because their customs and language are different from others and because their economic sources rely on planters of betel nuts and rubber, the residents are distributed into living in mountain settlements and temporary dormitories. In addition to the seasonal migration for planting in the local area, other migration opportunities are limited but relatively stable. In the malaria control stage, the Hainan island mountain workers population is infected with malaria. Malaria control researchers previously conducted interventions and achieved good results in the research stage [10-14,35,36]. Chen et al. showed that, after the intervention, the malaria-related proper KAP rate is improved; for example, the bed net use rate increased from $26.8 \%$ to $72.6 \%$, and the annual parasite incidence (API) of malaria declined from $3.5 \%$ in 1994

Table 6 Malaria-related KAPs of the mountain worker populations laterally compared in different areas before and after intervention

\begin{tabular}{|c|c|c|c|c|c|c|c|c|c|c|c|c|c|}
\hline \multirow[t]{3}{*}{ Gender } & \multirow[t]{3}{*}{ Content } & \multicolumn{6}{|c|}{ Before intervention } & \multicolumn{6}{|c|}{ After intervention } \\
\hline & & \multicolumn{2}{|c|}{ Testing area } & \multicolumn{2}{|c|}{ Control area } & \multirow[t]{2}{*}{$x^{2}$} & \multirow[t]{2}{*}{$p$} & \multicolumn{2}{|c|}{ Testing area } & \multicolumn{2}{|c|}{ Control area } & \multirow[t]{2}{*}{$x^{2}$} & \multirow[t]{2}{*}{$p$} \\
\hline & & $\mathbf{n}$ & $\%$ & $\mathbf{n}$ & $\%$ & & & $\mathbf{n}$ & $\%$ & $\mathbf{n}$ & $\%$ & & \\
\hline \multirow[t]{3}{*}{ Male } & $\mathrm{K}$ & 121 & 38.30 & 84 & 46.40 & 3.13 & 0.08 & 249 & 84.40 & 91 & 45.30 & 84.92 & $0.00^{*}$ \\
\hline & $A$ & 112 & 35.40 & 75 & 41.40 & 1.76 & 0.18 & 257 & 87.10 & 93 & 46.30 & 96.04 & $0.00^{*}$ \\
\hline & $P$ & 140 & 44.30 & 81 & 44.80 & 0.01 & 0.92 & 263 & 89.20 & 84 & 41.80 & 127.60 & $0.00^{*}$ \\
\hline \multirow[t]{3}{*}{ Female } & K & 85 & 37.00 & 69 & 34.80 & 0.21 & 0.65 & 245 & 94.20 & 70 & 36.50 & 174.51 & $0.00^{*}$ \\
\hline & $A$ & 90 & 39.10 & 74 & 37.40 & 0.14 & 0.71 & 251 & 96.50 & 80 & 41.70 & 169.63 & $0.00^{*}$ \\
\hline & $P$ & 95 & 41.30 & 87 & 43.90 & 0.30 & 0.58 & 249 & 95.80 & 82 & 42.70 & 158.62 & $0.00^{*}$ \\
\hline
\end{tabular}

${ }^{*} p<0.01$.

Testing area 546 persons (male, 316; female, 230) and control area 379 persons (male, 181; female, 198) participated in the survey before the intervention, testing area 555 persons (male, 295; female, 260) and control area 393 persons (male, 201; female, 192) participated in the survey after the intervention. 
Table 7 Malaria-related KAPs of the mountain worker populations longitudinally compared in different areas before and after intervention

\begin{tabular}{|c|c|c|c|c|c|c|c|c|c|c|c|c|c|}
\hline \multirow[t]{3}{*}{ Gender } & \multirow[t]{3}{*}{ Content } & \multicolumn{6}{|c|}{ Testing area } & \multicolumn{6}{|c|}{ Control area } \\
\hline & & \multicolumn{2}{|c|}{ Before intervention } & \multicolumn{2}{|c|}{ After intervention } & \multirow[t]{2}{*}{$x^{2}$} & \multirow[t]{2}{*}{$p$} & \multicolumn{2}{|c|}{ Before intervention } & \multicolumn{2}{|c|}{ After intervention } & \multirow[t]{2}{*}{$x^{2}$} & \multirow[t]{2}{*}{$p$} \\
\hline & & $\mathrm{N}$ & $\%$ & $\mathrm{~N}$ & $\%$ & & & $\mathrm{~N}$ & $\%$ & $\mathrm{~N}$ & $\%$ & & \\
\hline \multirow[t]{3}{*}{ Male } & K & 121 & 38.30 & 249 & 84.40 & 135.84 & $0.00^{*}$ & 84 & 46.40 & 91 & 45.30 & 0.05 & 0.82 \\
\hline & A & 112 & 35.40 & 257 & 87.10 & 170.33 & $0.00^{*}$ & 75 & 41.40 & 93 & 46.30 & 0.90 & 0.34 \\
\hline & $P$ & 140 & 44.30 & 263 & 89.20 & 136.67 & $0.00^{*}$ & 81 & 44.80 & 84 & 41.80 & 0.34 & 0.56 \\
\hline \multirow[t]{3}{*}{ Female } & K & 85 & 37.00 & 245 & 94.20 & 182.05 & $0.00^{*}$ & 69 & 34.80 & 70 & 36.50 & 0.11 & 0.74 \\
\hline & A & 90 & 39.10 & 251 & 96.50 & 190.07 & $0.00^{*}$ & 74 & 37.40 & 80 & 41.70 & 0.75 & 0.39 \\
\hline & $P$ & 95 & 41.30 & 249 & 95.80 & 173.07 & $0.00^{*}$ & 87 & 43.90 & 82 & 42.70 & 0.06 & 0.81 \\
\hline
\end{tabular}

${ }^{*} p<0.01$.

Testing area 546 persons (male, 316; female, 230) and control area 379 persons (male, 181; female, 198) participated in the survey before the intervention, testing area 555 persons (male, 295; female, 260) and control area 393 persons (male, 201; female, 192) participated in the survey after the intervention.

to $1.1 \%$ in 1996 and $0.8 \%$ in 1997 [13]. Regarding health education, after a month of malaria knowledge intervention, the correct answer rate increased from $41.4 \%$ to 91.5\% [12]. However, after the intervention, related interventions cannot continue, especially given the low rate of malaria cases, and the proper malaria prevention-related $\mathrm{KAP}$ rate becomes poor again in the mountain worker population. In this study, the rate of proper malaria prevention-related KAP was $<50 \%$, and the following possible factors are considered: (1) Hainan is a tropical area, and because the weather is hot, people do not like to sleep under hanging bed nets; (2) the formal education of many mountain workers is very low, and they have an insufficient understanding of KAPs regarding malaria prevention; most of the knowledge relies on oral transmission, and after a long time, the workers will forget; (3) the mountain worker populations commonly communicate in their own dialect, and they are unaccustomed to Mandarin intervention measures; (4) certain prevention interventions are not suitable to their local festivals; (5) many mountain workers are mainly young and middle-aged, and their understanding of malaria is insufficient because they believe that health and strength can prevent malaria; and so on. Therefore, this study established that, for the core group and their members from this ethnicity, researchers at the county-level CDC, township farm village teams, and hospital and village clinic personnel, must give the participants rewards and conduct regular training to core group members 1-2 times per year in order to supervise and promote the long-term effects and to ensure that the preventive measures are as long-term and continuous as possible, as evidenced in this study of BCC strategy.

In this study, during the needs assessment for implementing $\mathrm{BCC}$ policies, the baseline levels of malariarelated KAP in mountain worker populations in Hainan were determined for use as a basis in developing related materials and methods. This intervention model, which correlates KAP with malaria control and prevention, has received considerable attention and promotion in the past 10 years [37], and several other countries have conducted related policies in East Asia, including Myanmar, Cambodia, and Malawi [38-40]. Of course, in addition to the above factors affecting the malaria-related KAP of residents, the mode of promotion and education, the hardware and facilities at health institutions, and social and cultural factors may also affect the effectiveness of malaria-related KAP intervention. For example, this study found that in the test sites, the majority of mountain workers of the Li ethnicity usually communicate in the Hainan language because they cannot understand or rarely use Mandarin. This suggests that when healthrelated educational and promotional materials and methods are developed, they should be fully integrated in the local linguistic and cultural structures. Furthermore, feedback on the BCC interventional media showed that

Table 8 Comparison of the IFAT and blood smear test changes before and after intervention

\begin{tabular}{|c|c|c|c|c|c|c|}
\hline \multirow[t]{2}{*}{ Group } & \multirow[t]{2}{*}{ Population } & \multicolumn{3}{|c|}{ IFAT } & \multicolumn{2}{|c|}{ GMRT } \\
\hline & & Number testing positive (\%) & $x^{2}$ & $P$ & Positive & Total \\
\hline \multirow[t]{2}{*}{ Testing area } & 546 & $22(4.03)$ & 6.95 & $<0.01$ & 27.41 & 10.42 \\
\hline & 555 & $8(1.44)$ & & & 21.81 & 10.11 \\
\hline \multirow[t]{2}{*}{ Control area } & 379 & $24(6.33)$ & 0.34 & $>0.05$ & 25.94 & 10.62 \\
\hline & 393 & $21(5.34)$ & & & 24.38 & 10.49 \\
\hline
\end{tabular}

IFAT $=$ Indirect fluorescent antibody test. GMRT $=$ Geometric mean reciprocal titer. IFAT Positive: $\geq 1: 20$. 


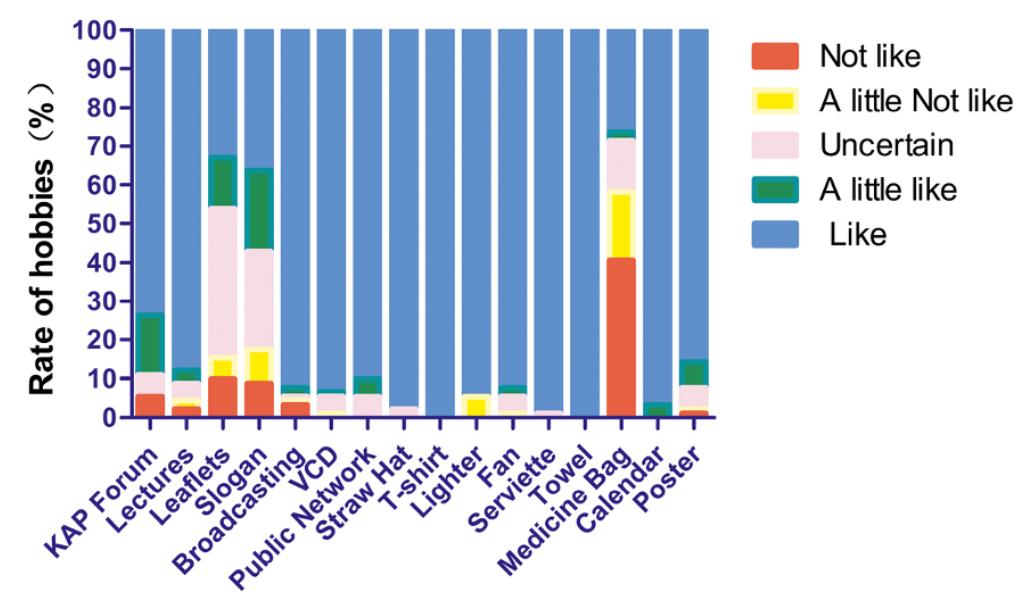

Figure 4 The rate of mountain worker hobbies feedback to BCC intervention content. *After the intervention, 100 mountain workers were randomly selected to provide feedback, 94 completed questionnaires, 91 qualified questionnaires.

malaria-related promotional materials should be selected based on the lifestyles and productivity of the group in question; some well-received items included straw hats, T-shirts, lighters, and fans. For audio-visual promotional materials such as VCDs and public broadcasting, including Hainan minority language features (such as using Hainan and Li dialects) and images and sounds of local customs (such as local festivals) made the materials more acceptable and likable. Otherwise, the implementation of the anti-malaria measures may be affected, and the desired goals may not be reached. These results are in agreement with the results of similar research conducted in rural areas of Hubei, China [41]. Regarding other aspects of malaria serology, the BCC strategy was found to be statistically significant $(P<0.01)$ through a comparison of the IFAT and blood smear test changes before and after the intervention. Furthermore, the positive and overall GMRTs shows little change because all of the malaria-control measures are better in the testing and control areas; however, the $\mathrm{BCC}$ strategy is more effective than the conventional measures [33].

The survey results showed that the mountain workers in Hainan had a better understanding of malarial symptoms and transmission pathways than did the people in the rural areas of Hubei, China $[42,43]$. One possible explanation is that the mountain workers were mainly planters who must go into the mountains frequently and thus have a higher risk of infection. The aim of the BCC intervention in this study was to improve the ability of the mountain workers themselves to prevent malaria, especially by seeking medical care promptly, using appropriate medication, and utilizing ITNs and LLTNs [44-47]. In the test sites, the majority of mountain workers showed significant improvement in malariarelated KAP indices after intervention; this finding is similar to the results of studies conducted in Malaysia,
Bhutan, Vietnam, and Swaziland [48-51]. In contrast, although the living conditions in areas with concentrated ethnic minority populations have gradually improved in the past few years, and mountain houses and straw huts are decreasing in number due to the government's efforts to improve dangerous housing conditions, these surveys showed that mosquito protection measures, such as household bed nets and screen windows, are rarely used, and the use of preventative medication and night-time mosquito protection when going into the mountains is not ideal either. Related studies suggest the importance of mosquito protection in living quarters [52,53].

In this study, implementing BCC policies through mountain-worker community participation achieved good results. Malaria prevention core groups were established, consisting of county-level CDC, township farm village teams, and hospitals and village clinic personnel; strengthened the community outreach mobilization; implemented periodic coordination and training on routine handling procedures upon discovery of malaria; expanded the core group members by influencing the family members and coworkers of mountain workers in the region; and used a malaria reporting reward system to ensure that the policies were implemented. The study also relied on the public health broadcasting system, which the Hainan government had installed in health care facilities, community health service stations, urban and rural hospitals, pharmacies and other public places. Malaria prevention facts were also put on rolling display every day on LCD digital media platforms, and the intervention was effective. These results are similar to those achieved by implementing BCC policies to promote malaria prevention KAPs in the South Pacific island of Vanuatu and in malaria-endemic areas of India [53,54]. At the same time, studies also suggest that when promoting health education, the positive role played by 
women and family members in community interventions must be emphasized $[55,56]$.

China's action plan to eliminate malaria (2010-2020) set up a specific timetable for the elimination of malaria. Developing materials and methods according to local conditions for malaria-related interventions using comprehensive $\mathrm{BCC}$ models can provide both a theoretical basis and practical methods for eliminating malaria in Hainan. However, this study has certain limitations: the positive malaria antibody cases in the present study were not necessarily actual malaria cases, malaria itself has more complex epidemic factors, this study only selected representative factors among the various factors of KAP, and misunderstanding by the survey subjects might have affected the investigation. The present investigation does, however, provide a scientific basis and theoretical reference for employing the $\mathrm{BCC}$ strategy to eliminate malaria in Hainan.

\section{Competing interests}

The authors declare that they have no competing interests.

\section{Authors' contributions}

$\mathrm{HCH}$, DJW, WSQ conceived this study and drafted the first version of this manuscripts. HXM and WGZ gave technical assists. ZW, SDW, CCX participated the survey and data collection. LYC polished and adjusted figures and tables in this manuscripts. All of the authors have read and approved the final manuscript.

\section{Acknowledgements}

This study received a financial support from the Hainan Provincial Scientific Research Grant (No. 309074 and 813251). We would like to thank the staff from Wanning CDC, Dongfang CDC, Ledong CDC.

Received: 21 February 2014 Accepted: 7 July 2014

Published: 13 July 2014

\section{References}

1. Liang ZQ, Xu DM, Chen B: [Geography of Hainan island] (in Chinese). The yearbook of Hainan provincial People's government, China 2012, 12:39-64.

2. Xu JW, Xia M, Tao H, Wu XH, Yang JQ, Yang TZ: [Surveys on potential partners of IEC for malaria control and their perceptions toward malaria] (in Chinese). Chin Trop Med 2004, 2:172-174.

3. Chen WJ, WU KC, Lin MH, Li CX: [Great achievements of anti-malaria for a half century and the present technical problems in Hainan Island] (in Chinese). Chin Trop Med 2007, 7:2013-2017.

4. WHO: World malaria report 2012. Geneva: World Health Organization; 2011. http://www.who.int/malaria/publications/atoz/9789241564403/en/.

5. Xia ZG, Yang MN, Zhou SS: [Malaria Situation in the People's Republic of China in 2011](in Chinese). Zhongguo Ji Sheng Chong Xue Yu Ji Sheng Chong Bing Za Zhi 2012, 30:419-422.

6. Gorgui D, Xu YH, Patrick NK, Li C, Gan XM, Nie SF: Evaluation of the effectiveness of intervention for malaria control in rural areas in China. Global J Health Sci 2010, 2:41-45.

7. Jiao Y, Meng QY: [Analysis on situation, policy intervention and challenge of malaria control in China] (in Chinese). Chin Prim Health Care 2006, 20:20-22.

8. Zhang S, Xing HJ, Zu CC: [Present status of malaria control resources in China](in Chinese). Chin J Pathogen Biology 2010, 5:627-629.

9. Cai XZ: [Malaria control in Hainan island during the past 40 years](in Chinese). Hainan Med J 1993, 4:1.

10. Chen WJ, Wu KC, Lin MH, Li CX: [Great achievement of anti-malaria for a half century and the present problem in Hainan Island](in Chinese). Chin Trop Med 2007, 7:2013-2016.
11. Lin MH, Chen WJ, Lang CX: [A field study on "mountain-acquired malaria" and its control in Hainan province] (in Chinese). Chin J Parasit Parasitic Dis 1999, 12:6-8.

12. He YJ, Cui YQ, Tang DH: [Study on the intervention measures for the control of malaria by health education and community participation] (in Chinese). Chin J Parasitic Disease Control 1996, 9:264-267.

13. Chen WJ, Wu KC, Lin MH, Tang LH, Gu ZH, Wang SQ, Lan CX, Lan XH, Li HP, Hung MS, Chen $X$, Sheng HF: [A pilot study on malaria control by using a new strategy of combining strengthening infection source treatment and health education in mountainous areas of Hainan province] (in Chinese). Chin J Parasit Parasitic Dis 1999, 17:1-4.

14. Wu KC, Tang LH, Chen WJ, Liu DQ, Lin MH, Gu ZC, Lan CX, He YJ, Wang ZG, Chen GZ, Cai XZ, Deng D: [Studies on current characteristics of malaria endemic in mountainous areas of Hainan province]. Chin J Parasitic Disease Control 1998, 11:241-245.

15. Gao CY, Cai GJ, Han GH, Yang XW, Liu L, Jiang ZJ: [Descriptive analysis of trends of malaria prevalence in China from 1950 to 2001] (in Chinese). Chin J Public Health 2003, 19:725-726.

16. Ministry of Health, People's Republic of China: China Action Plan for Malaria Elimination. [http://www.nhfpc.gov.cn/jkj/s5873/201005/ f84f1c4b0f32420990d23b65a88e2d87.shtml]. (In Chinese).

17. Li YN, Wen L, Li CY, Zhang WY, Sun HL, Zhou W, Li SL, Sun YS: ]Descriptive analysis of trends of malaria prevalence in China from 2006 to 2010] (in Chinese). Chin J Public Health 2013, 29:263-265.

18. Lin H, Lu L, Tian L, Zhou S, Wu H, Bi Y, Ho S, Liu Q: Spatial and temporal distribution of falciparum malaria in China. Malar J 2009, 8:130.

19. WHO: Indoor residual spraying: Use of indoor residual spraying for scaling up global malaria control and elimination. Geneva, Switzerland: World Health Organization; 2006

20. The Global Fund to Fight AIDS, Tuberculosis and Malaria. http://www. theglobalfund.org/en/fundingdecisions/\#5.

21. [Criteria for control and elimination of malaria, Ministry of Health, People's Republic of China] (in Chinese). http://www.nhfpc.gov.cn/zwgkzt/s9491/ 201106/51932/files/10fa73fa12424fbb9a2c4c04d08e2290.pdf.

22. Lin MH, Chen WJ, Lan CX, Gu ZC, Li HP, Lan XH, Huang MS, Chen X, Cai XZ, Wu KC: [A field study on "mountain acquired malaria" and its control in Hainan province] (in Chinese). Chin J Parasit Parasitic Dis 1999, 12:6-8.

23. Long Y, Wang S, Wu K, Xu D, Li H, Wang G, Yan Y: Epidemic Distribution and Variation of Plasmodium falciparum and Plasmodium vivax malaria in Hainan, China during 1995-2008. Am J Trop Med Hyg 2012, 87:646-654.

24. Lin CF, Lin SG, Fu ZL, Ji WD, Li HS: [Survey of the situation of malaria prevention in the populations working on the mountains and sleeping there at night in malaria endemic area of Ledong County] (in Chinese). Chin Trop Med 2005, 5:257.

25. Mugisa M, Muzoora A: Behavioral change communication strategy vital in malaria prevention interventions in rural communities: Nakasongola district, Uganda. Pan Afr Med J 2012, 13(Suppl 1):2.

26. Cao J, ZHou SS, ZHou HY, Yu XB, Tang LH, Gao Q: [Malaria from control to elimination in China: Transition of goal, strategy and interventions] (in Chinese). Chin J Schistosomiasis Control 2013, 25:439-443.

27. Moonen B, Cohen JM, Snow RW, Slutsker L, Drakeley C, Smith DL, Abeyasinghe RR, Rodriguez MH, Maharaj R, Tanner M, Targett G: Operational strategies to achieve and maintain malaria elimination. Lancet 2010, 376:1592-1603.

28. Cotter C, Sturrock HJ, Hsiang MS, Liu J, Phillips AA, Hwang J, Gueye CS, Fullman N, Gosling RD, Feachem RG: The changing epidemiology of malaria elimination: new strategies for new challenges. Lancet 2013, 382:900-911.

29. Xu JW, Wu XH, Wei C, Pricha P, Tao H: [Study on the use of insecticidetreated bed nets among ethnical minority residents by behavior change communication strategies] (in Chinese). Chin J Vector Biol Control 2009, 20:433-435.

30. Family Health International Institute for HIV/AIDS: Behavior change communication (BCC) for HIV/AIDs - strategic framework 2002. Arlington, Virginia, USA: Family Health International Institute for HIV/AIDS; 2002.

31. Kaneko A: A community-directed strategy for sustainable malaria elimination on islands: short-term MDA integrated with ITNs and robust surveillance. Acta Trop 2010, 114:177-183.

32. African Medical And Research Foundation(AMREF): Survey on Kakooge and Nakitoma Sub counties Nakasongola District. Nairobi, Kenya: AMREF final evaluation report; 2010. 
33. Bureau of Disease Prevention and Control of Ministry of Health, P.R.C: [Manual of Malaria Control] (in Chinese), 3rd. Beijing: People's Health Publishing House; 2007:248

34. Huang WZ, Luo MZ, Zhou MX, Chen FQ, Xuan SZ: [Indirect fluorescent antibody test with two different antigens in a single cross-sectional survey of malaria] (in Chinese). Chin J Parasitol Parasit Dis 1985, 3:181-183.

35. Cai XZ, Deng D, Wu KC, Tang LH, Lan CX, Gu ZC, He YJ, Wang K, Wu DL, Du JW: [A study on human behavior and socioeconomic factors affecting malaria transmission and control in Qiong zhong, Hainan] (in Chinese). Chin J Parasitology Parasitic Diseases 1995, 13:89-93.

36. Chen WJ, Shi PJ, Wu KC, Deng D, Tang LH, Cai XZ, Gu ZC, Si YZ, Lin MH, Yan WX: [An unconditional logistic multi-regression analysis of socioeconomic factors affecting malaria prevalence in mountainous areas of Hainan province] (in Chinese). Chin J Parasitology Parasitic Diseases 1995, 8:161-164

37. Zhang M, Liu Z, He H, Luo L, Wang S, Bu H, Zhou X: Knowledge, attitudes, and practices on malaria prevention among Chinese international travelers. J Travel Med 2011, 18:173-177.

38. Uza M, Phommpida S, Toma T, Takakura M, Manivong K, Bounyadeth S, Kobayashi J, Koja Y, Ozasa Y, Miyagi I: The relationship between knowledge, behavior of malaria prevention and morbidity in Laos. Southeast Asian J Trop Med Pub Health 2002, 33:246-254.

39. Mazigo HD, Obasy E, Mauka W, Manyiri P, Zinga M, Kweka EJ, Mnyone LL, Heukelbach J: Knowledge, attitudes and practices about malaria and its control in rural Northwest Tanzania. Malar Res Treat 2010, 2010:794261.

40. Njama D, Dorsey G, Guwatudde D, Kigonya K, Greenhouse B, Musisi S, Kamya M: Urban malaria: primary caregivers' knowledge, attitudes, practices and predictors of malaria incidence in a cohort of Ugandan children. Trop Med Int Health 2003, 8:685-692.

41. Seck I, Fall IS, Faye A, Ba O, Tal-Dia A: [Malaria knowledge, attitudes and practices among women living in the rural area of Poponguine, Senegal] (in French). Med Trop (Mars) 2008, 68:629-633.

42. Qiu Q, Hu XL, Wu MH, Cai L, Huang GQ, Yuan FY, Xu YH: [Knowledge and demand of malaria prevention in rural residents of Hubei province] (in Chinese). Chin J Public Health 2009, 25:229-230.

43. Lin CF, Li KJ, He CH: [Survey of health behavior and demands for malaria control in population working and sleeping on mountain in Hainan] (in Chinese). Chin Trop Med 2009, 9:630-631.

44. Xu JW, Zhong YC: [The relationship of malaria causes with malaria prevention and knowledge in seeking treatment and the influential factors] (in Chinese). Chin Trop Med 2004, 4:531-534

45. Snow RW, Guerra CA, Noor AM, Myint HY, Hay SI: The global distribution of clinical episodes of Plasmodium falciparum malaria. Nature 2005, 434:214-217.

46. Faye O, Lo M, Diop Bah IB, Dieng T, Dieng Y, N'Dir O, Diallo S: [Knowledge and treatment of malaria in rural Senegal] (in French). Med Trop (Mars) 1997, 57:161-164

47. Al-Adhroey AH, Nor ZM, Al-Mekhlafi HM, Mahmud R: Opportunities and obstacles to the elimination of malaria from Peninsular Malaysia: knowledge, attitudes and practices on malaria among aboriginal and rural communities. Malar J 2010, 9:137

48. Hlongwana KW, Mabaso ML, Kunene S, Govender D, Maharaj R: Community knowledge, attitudes and practices (KAP) on malaria in Swaziland: A country earmarked for malaria elimination. Malar J 2009, 8:29.

49. Anh NQ, Hung Le $X$, Thuy HN, Tuy TQ, Caruana SR, Biggs BA, Morrow M: KAP surveys and malaria control in Vietnam: findings and cautions about community research. Southeast Asian J Trop Med Public Health 2005, 36:572-577.

50. Tobgay T, Pem D, Dophu U, Dumre SP, Bangchang KN, Torres CE: Community-directed educational intervention for malaria elimination in Bhutan: quasi-testing study in malaria endemic areas of Sarpang district. Malar J 2013, 12:132

51. Minja H, Schellenberg JA, Mukasa O, Nathan R, Abdulla S, Mponda H, Tanner M, Lengeler C, Obrist B: Introducing insecticide-treated nets in the Kilonbero Valley, Tanzania: the relevance of local knowledge and practice for an Information, Education and Communication (IEC) compaign. Trop Med Int Health 2001, 6:614-623.

52. Halima AM: Social science research in malaria prevention, management and control in the last two decades: an overview. Acta Trop 2005, 95:292-297.

53. Atkinson JA, Fitzgerald L, Toaliu H, Taleo G, Tynan A, Whittaker M, Riley I, Vallely A: Community participation for malaria elimination in Tafea
Province, Vanuatu: Part I. Maintaining motivation for prevention practices in the context of disappearing disease. Malar J 2010, 9:93.

54. Ghosh SK, Patil RR, Tiwari S, Dash AP: A community-based health education programme for bio-environmental control of malaria through folk theatre (Kalajatha) in rural India. Malar J 2006, 5:123.

55. Chirdan OO, Zoakah Al, Ejembi CL: Impact of health education on home treatment and prevention of malaria in Jengre, North Central Nigeria. Ann Afr Med 2008, 7:112-119.

56. Rose K, Diana M, Wilson O: Supporting formal education to improve quality of health care provided by mothers of children with malaria in rural western Kenya. J Infect Dev Ctries 2009, 3:548-553.

doi:10.1186/1475-2875-13-273

Cite this article as: He et al:: Eliminating Plasmodium falciparum in Hainan, China: a study on the use of behavioural change communication intervention to promote malaria prevention in mountain worker populations. Malaria Journal 2014 13:273.

\section{Submit your next manuscript to BioMed Central and take full advantage of:}

- Convenient online submission

- Thorough peer review

- No space constraints or color figure charges

- Immediate publication on acceptance

- Inclusion in PubMed, CAS, Scopus and Google Scholar

- Research which is freely available for redistribution 